\title{
Moderate Protein Restriction Protects Against Focal Cerebral Ischemia in Mice by Mechanisms Involving Anti-inflammatory and Anti-oxidant Responses
}

\author{
Tayana Silva de Carvalho ${ }^{1}$ - Eduardo H. Sanchez-Mendoza ${ }^{1}$ - Luiza M. Nascentes ${ }^{1}$. Adriana R. Schultz Moreira ${ }^{1}$. \\ Maryam Sardari $^{1} \cdot$ Egor Dzyubenko $^{1} \cdot$ Christoph Kleinschnitz $^{1}$ • Dirk M. Hermann ${ }^{1}$ (D)
}

Received: 1 April 2019 / Accepted: 10 June 2019/Published online: 1 July 2019

(C) The Author(s) 2019

\begin{abstract}
Food composition influences stroke risk, but its effects on ischemic injury and neurological deficits are poorly examined. While severe reduction of protein content was found to aggravate neurological impairment and brain injury as a consequence of combined energy-protein malnutrition, moderate protein restriction not resulting in energy deprivation was recently suggested to protect against perinatal hypoxia-ischemia. Male C57BL6/j mice were exposed to moderate protein restriction by providing a normocaloric diet containing $8 \%$ protein (control: $20 \%$ protein) for 7,14 , or 30 days. Intraluminal middle cerebral artery occlusion was then induced. Mice were sacrificed $24 \mathrm{~h}$ later. Irrespective of the duration of food modification (that is, 7-30 days), protein restriction reduced neurological impairment of ischemic mice revealed by a global and focal deficit score. Prolonged protein restriction over 30 days also reduced infarct volume, brain edema, and blood-brain barrier permeability and increased the survival of NeuN+ neurons in the core of the stroke (i.e., striatum). Neuroprotection by prolonged protein restriction went along with reduced brain infiltration of CD45+ leukocytes and reduced expression of inducible NO synthase and interleukin-1ß. As potential mechanisms, increased levels of the NAD-dependent deacetylase sirtuin-1 and anti-oxidant glutathione peroxidase-3 were noted in ischemic brain tissue. Irrespective of the protein restriction duration, a shift from pro-oxidant oxidative stress markers (NADPH oxidase-4) to anti-oxidant markers (superoxide dismutase-1/2, glutathione peroxidase-3 and catalase) was found in the liver. Moderate protein restriction protects against ischemia in the adult brain. Accordingly, dietary modifications may be efficacious strategies promoting stroke outcome.
\end{abstract}

Keywords Cerebral metabolism $\cdot$ Ischemic stroke $\cdot$ Middle cerebral artery occlusion $\cdot$ Neuroprotection $\cdot$ Oxidative stress $\cdot$ Protein intake

\section{Introduction}

Alimentation with protein-rich animal products has greatly fostered human development. At the same time, protein-rich nutrition, specifically with red meat, might elevate health risks, as indicated by a number of population-based studies. Regarding stroke, the Nurses' Health Study and Health

Electronic supplementary material The online version of this article (https://doi.org/10.1007/s12035-019-01679-6) contains supplementary material, which is available to authorized users.

Dirk M. Hermann

dirk.hermann@uk-essen.de

1 Department of Neurology, University Hospital Essen, Hufelandstr. 55, 45122 Essen, Germany
Professionals Follow-Up Study, which prospectively examined 84,010 women and 43,150 men more than 20 years, reported that one serving of red meat per day increases the incidence of stroke events by a factor of 1.13 (95\%-confidence interval (CI) 1.04-1.22) [1]. This observation was later confirmed in a meta-analysis on 329,495 subjects followed up over 8-26 years, which found a 1.11 (1.06-1.16)-fold increase of stroke events per red meat serving [2].

The question how food composition influences the severity of ischemic injury and neurological impairment, once a stroke has occurred, has major importance for stroke management. Yet, little data exist on this issue. It is well established that severe malnutrition characterized by low body mass index (BMI) and hypoalbuminemia is associated with poor stroke recovery [3]. How more moderate changes in food intake that are not associated with BMI changes influence ischemic 
injury is unknown. Randomized studies are lacking on this issue. The diversity of human nutrition habits possibly precludes insights from clinical cohort studies $[1,2]$.

In rats and gerbils, the delivery of diets containing $0.5-2 \%$ protein 3 to 4 weeks in models of global [4-6] or focal [7] cerebral ischemia compromised neurological recovery, increased brain inflammation, increased neuronal injury, and reduced brain plasticity. Yet, such severe protein restriction results in a reduction in the total amount of food ingested, since the animals refuse this chow [4-7]. In such animals, combined protein-energy malnutrition is noted. A single rat study so far examined consequences of a more moderate diet containing $7 \%$ protein, which, when administered during pregnancy and lactation to mothers, reduced brain injury but augmented sensorimotor deficits of offspring exposed to unilateral cerebral hypoxia-ischemia at 7 days post-birth [8]. How such moderate protein restriction influences ischemic injury and neurological deficits in the adult brain was unknown. By exposing mice to a normocaloric diet containing $8 \%$ protein, which we subsequently exposed to intraluminal middle cerebral artery occlusion (MCAO), we now examined this question. Our hypothesis was that moderate protein restriction reduces neurological deficits and brain injury.

\section{Materials and Methods}

\section{Legal Issues, Statistical Planning, and Randomization}

Experiments were approved by local government authorities (Bezirksregierung Düsseldorf) in accordance with E.U. guidelines (Directive 2010/63/EU) for the care and use of laboratory animals. Sample size calculations determined that 12 animals per group were required for the neurological examinations and histochemical studies, given that the effect size was 1.167 , the alpha error was 5\%, and the beta error (1-statistical power) was $20 \%$. Experimenters were blinded by a third person not involved in the assessments randomizing the animals, weighing and providing the food pellets. All animals survived the stroke surgery. To minimize the use of laboratory animals, all animals were used both for behavioral studies and histochemical or molecular biological analyses.

\section{Animal Nutrition and Murinometrics}

Thirty-six adult male C57BL6/j mice ( 8 weeks, 26-30 g; Harlan-Netherlands, Rossdorf, Germany) were randomized to two diets: (a) normal nutrition $(\mathrm{C} 1000 ; 3518 \mathrm{kcal} / \mathrm{kg}$, $20 \%$ (by weight) casein, $13 \%$ (by weight) fat; Altromin, Lage, Germany) and (b) protein-reduced nutrition (C1003; $3541 \mathrm{kcal} / \mathrm{kg}, 8 \%$ casein, $13 \%$ fat; Altromin). Diets and water were delivered ad libitum over 7, 14, or 30 days. These durations were chosen to obtain a thorough understanding of the animals' adaptation to the food modification. Animals were then submitted to $30 \mathrm{~min}$ intraluminal MCAO. Throughout the study, animals were housed in single cages (Green line IVC Sealsafe PLUS mouse; Tecniplast, Hohenpeißenberg, Germany) in a $12 \mathrm{~h} / 12 \mathrm{~h}$ light/dark cycle, in order to quantify food intake. Food consumption and calorie intake were measured daily. Body weight and BMI were measured weekly. Body (i.e., nose-anus) length was determined prior to diet exposure for evaluating BMI (in $\mathrm{kg} / \mathrm{cm}^{2}$ ) [9].

\section{Experimental Procedures}

Mice were anesthetized with $1.0-1.5 \%$ isoflurane $\left(30 \% \mathrm{O}_{2}\right.$, remainder $\mathrm{N}_{2} \mathrm{O}$ ). Rectal temperature was maintained between 36.5 and $37.0^{\circ} \mathrm{C}$ using a feedback-controlled heating system. Cerebral laser Doppler flow (LDF) was recorded using a flexible probe (Perimed, Järfälla, Sweden) attached to the skull overlying the core of the middle cerebral artery territory. A midline neck incision was made. The left common and external carotid arteries were isolated and ligated, and the internal carotid artery was temporarily clipped. A silicon-coated nylon monofilament $(0.21 \mathrm{~mm}$ tip diameter; Doccol, Sharon, MA, USA) was introduced through a small incision of the common carotid artery and advanced to the circle of Willis for MCAO $[10,11]$. Reperfusion was initiated by monofilament removal. Wounds were carefully sutured and anesthesia was discontinued. MCAO was induced during the day cycle of the animals in the surgery facility of the NeuroScienceLab. Behavioral abnormalities and clinical manifestations were checked eight-hourly until $24 \mathrm{~h}$ after MCAO. Twenty-four hours later, animals were evaluated using the Clark score [12], which captures general and focal neurological deficits. Immediately before animal sacrifice, plasma samples were obtained after $5 \mathrm{~h}$ fasting by cardiac puncture that were used for analysis of total cholesterol, low-density lipoprotein cholesterol (LDL), triglycerides, and glucose levels (ADVIA® 2400; Siemens, Erlangen, Germany). One set of animals ( $n=12$ / group) was transcardially perfused with normal saline followed by $4 \%$ paraformaldehyde for histochemical studies. Another set ( $n=6 /$ group) was transcardially perfused with normal saline for Western blots and real-time quantitative polymerase chain reaction (qPCR) studies. Brains were cut into $20-\mu \mathrm{m}$-thick coronal sections.

\section{Infarct Volumetry}

Coronal sections collected at millimeter intervals across the brain were stained with cresyl violet. Infarct volume was determined by subtracting the area of healthy tissue in the ischemic hemisphere from that in the contralesional hemisphere [11]. Considering that infarct volume was the most rigid stroke readout, infarct volume was defined as primary readout of this study. 


\section{Immunohistochemistry of IgG Extravasation}

Brain sections obtained from the rostrocaudal level of the midstriatum were rinsed for $20 \mathrm{~min}$ in $0.3 \% \mathrm{H}_{2} \mathrm{O}_{2}$ in $70 \%$ methanol/ 0.1 M phosphate-buffered saline (PBS), immersed in $0.1 \mathrm{M}$ PBS containing $5 \%$ bovine serum albumin (BSA) (05470; Sigma-Aldrich, Darmstadt, Germany), and incubated for $1 \mathrm{~h}$ in biotinylated anti-mouse $\operatorname{IgG}(1: 100$; Santa Cruz, Heidelberg, Germany), followed by diaminobenzidine tetrahydrochloride (DAB) (D5905; Sigma-Aldrich, Darmstadt, Germany) staining with an avidin-biotin complex peroxidase kit (Vectastain Elite; Vector Labs, Burlingame, CA, U.S.A.) [11]. IgG extravasation was analyzed by evaluating the area covered by $\operatorname{IgG}$ in the ischemic brain.

\section{Terminal Deoxynucleotidyl Transferase-Mediated dUTP Nick End Labeling}

Adjacent brain sections were subjected to terminal deoxynucleotidyl transferase-mediated dUTP nick end labeling (TUNEL) using a commercially available In Situ Cell Death Detection kit (Roche, Mannheim, Germany). TUNEL+, that is, DNA-fragmented cells were assessed under an inverted microscope equipped with Apotome optical sectioning (Zeiss Axio Observer.Z1) by counting the total number of labeled cells in the ischemic striatum [11].

\section{Immunohistochemistry for Neuronal, Microglial, Astrocytic, and Inflammation Markers}

Adjacent sections were immersed in $0.1 \mathrm{M}$ PBS containing $0.3 \%$ Triton X-100 (PBS-T) and 5\% normal donkey serum (D9663; Sigma-Aldrich, Darmstadt, Germany). Sections were incubated overnight at $4{ }^{\circ} \mathrm{C}$ in monoclonal rabbit anti-NeuN (1:400; ab177487; Abcam, Cambridge, UK), monoclonal rat anti-CD45 (1:200; 550,539; BD Biosciences, Heidelberg, Germany), polyclonal rabbit anti-ionized calcium binding adaptor protein (Iba)-1 (1:500; Wako Chemicals, Neuss, Germany), monoclonal rat anti-glial fibrillary acidic protein (GFAP) (1:200; 130,300; Invitrogen, Dublin, Ireland), or polyclonal rabbit anti-inducible nitric oxide synthase (iNOS) (1:100; sc-650, Santa Cruz, Heidelberg, Germany) antibodies that were detected with Alexa Fluor-488 or Alexa Fluor-594labeled secondary antibodies (NeuN, Iba-1, GFAP, iNOS) or biotinylated secondary antibodies followed by DAB staining with an avidin-biotin complex peroxidase kit (Vectastain Elite; Vector Labs, Burlingame, CA, U.S.A.) (CD45). NeuN, Iba-1, GFAP, and iNOS labeling were counterstained with 4',6diamidino-2-phenylindole (DAPI) (D9542; Sigma-Aldrich, Darmstadt, Germany). Sections were evaluated under a motorized Zeiss Axio Observer.Z1 inverted epifluorescence microscope equipped with Apotome optical sectioning (NeuN, Iba-1, GFAP, iNOS) or an Olympus X52 microscope (CD45) by counting the total number of NeuN+, CD45+, or iNOS+ cells in the striatum or analyzing the area covered by activated microglia (Iba-1) or reactive astrocytes (GFAP). The latter analysis was preferred to cell countings, since individual cells could not always unequivocally be discriminated. The latter data were shown as percent changes.

\section{Real-Time Quantitative Polymerase Chain Reaction (qPCR)}

From tissue samples harvested from the ischemic middle cerebral artery territory and liver, messenger RNA (mRNA) was extracted using the RNeasy Mini Kit (Qiagen, Hilden, Germany). mRNA was converted to cDNA using the highcapacity RNA-to-cDNA kit (Thermo Fisher Scientific, Waltham, MA, U.S.A). Real-time qPCR was performed in a StepOnePlus real-time PCR instrument (Thermo Fisher Scientific, Waltham, MA, USA) using primers designed or selected by the PubMed primer BLAST tool (https://blast. ncbi.nlm.nih.gov/) (Suppl. Table 1). Melting curves were used to confirm the efficiency of the primers. $\beta$-glucuronidase $(\beta$ Gluc) was used as housekeeping gene; brain and liver tissue from healthy mice served as control. Data were finally normalized that animals on normal diet were set as 1 . Results were quantified using the $2^{-\Delta \Delta C t}$ method [13]. PCR was performed in triplicates, of which mean values were computed for each animals.

\section{Western Blots}

During mRNA extraction, protein samples were collected after bromocholoropropane (B9673; Sigma-Aldrich, Darmstadt, Germany) separation. Ethanol was added and samples centrifuged at $12,000 \times \mathrm{g}$ for $5 \mathrm{~min}$. This procedure was repeated twice. The resulting pellet was suspended in $4 \%$ sodium dodecyl sulfate (SDS) (436,143; Sigma-Aldrich, Darmstadt, Germany). Protein content was measured using the Bradford method. Equal amounts of protein $(20 \mu \mathrm{g})$ were loaded on $10 \%$ SDS-polyacrylamide gels, submitted to SDSpolyacrylamide gel electrophoresis (PAGE), and transferred onto polyvinylidene fluoride (PVDF) membranes (Bio-Rad, Hercules, CA, USA). Membranes were blocked by $5 \%$ nonfat-dried milk (M7409; Sigma-Aldrich, Darmstadt, Germany) in $50 \mathrm{mM}$ Tris-buffered saline (TBS) containing 0.1\% Tween (P9416; Sigma-Aldrich, Darmstadt, Germany) for $1 \mathrm{~h}$ at room temperature, washed and incubated overnight at $4{ }^{\circ} \mathrm{C}$ with monoclonal rabbit anti-sirtuin-1 (Sirt-1; $1: 2000$; ab32441; Abcam, Cambridge, UK), polyclonal rabbit antiglutathione peroxidase-3 (Gpx-3; 1:2000; ab59524; Abcam, Cambridge, UK), and polyclonal rabbit anti- $\beta$-actin (1:10000; 4967; Cell Signaling, Frankfurt, Germany) antibody. The next day, membranes were washed and incubated with secondary donkey anti-rabbit antibody. Blots were revealed using a 
a
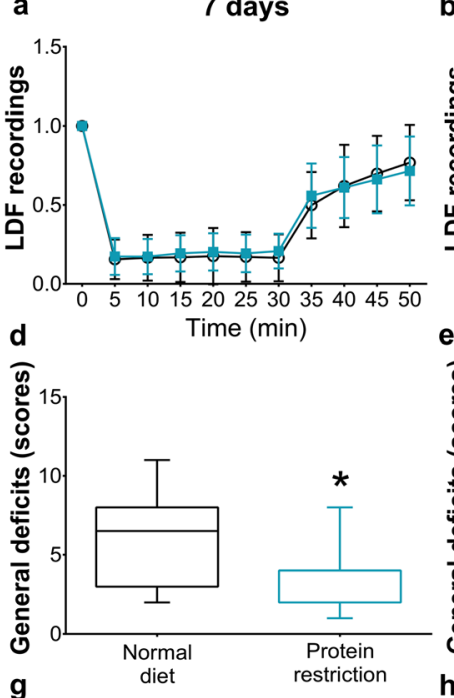

g

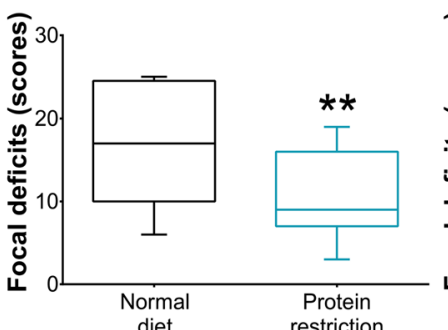

diet
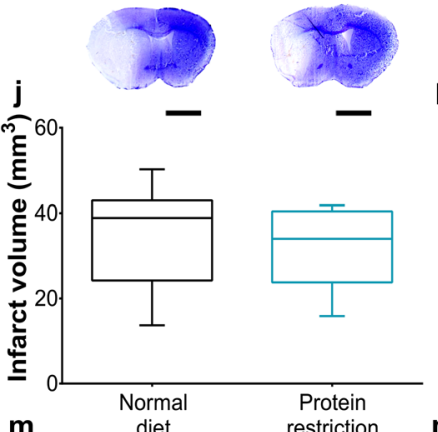

m diet $\quad \begin{gathered}\text { Protein } \\ \text { restriction }\end{gathered}$
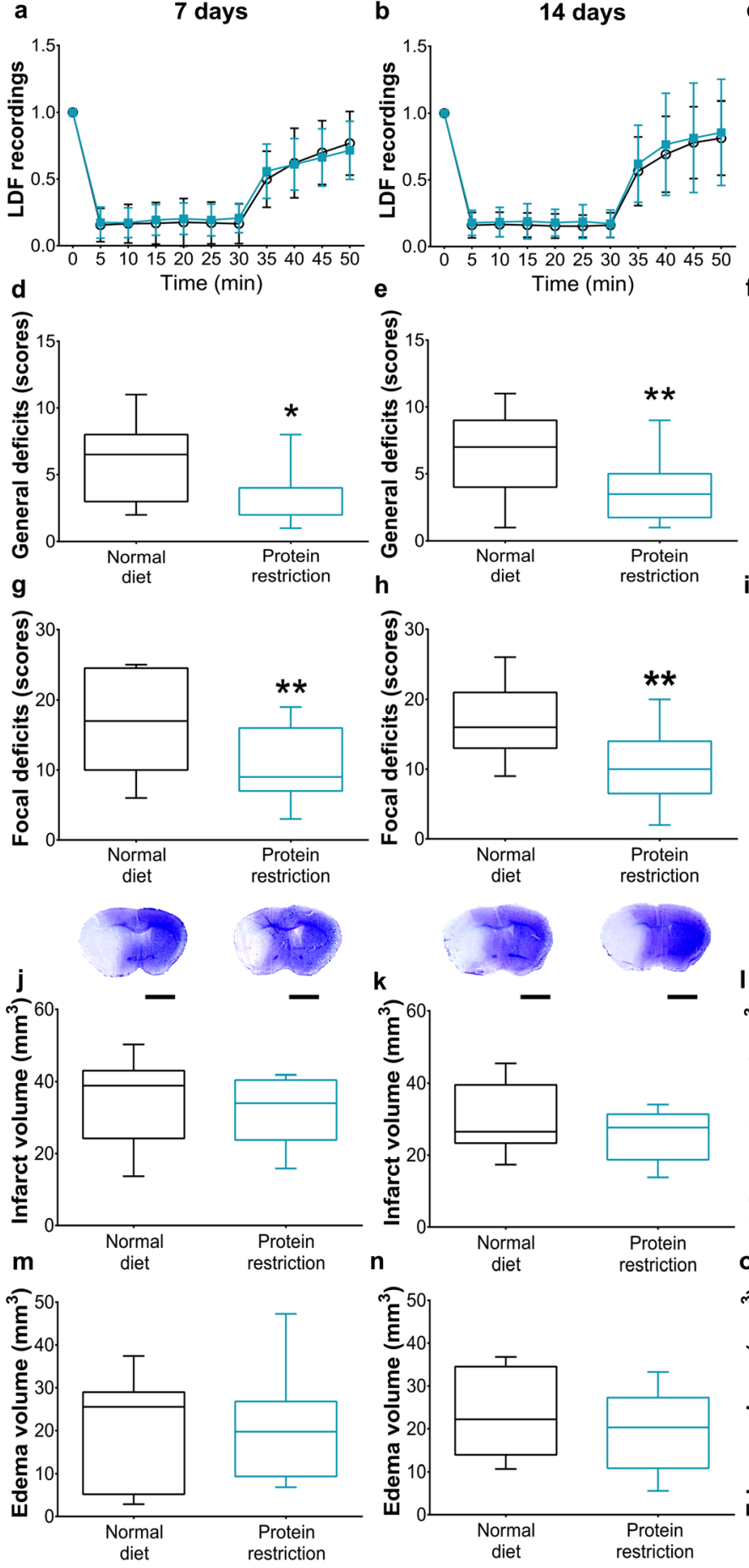

C
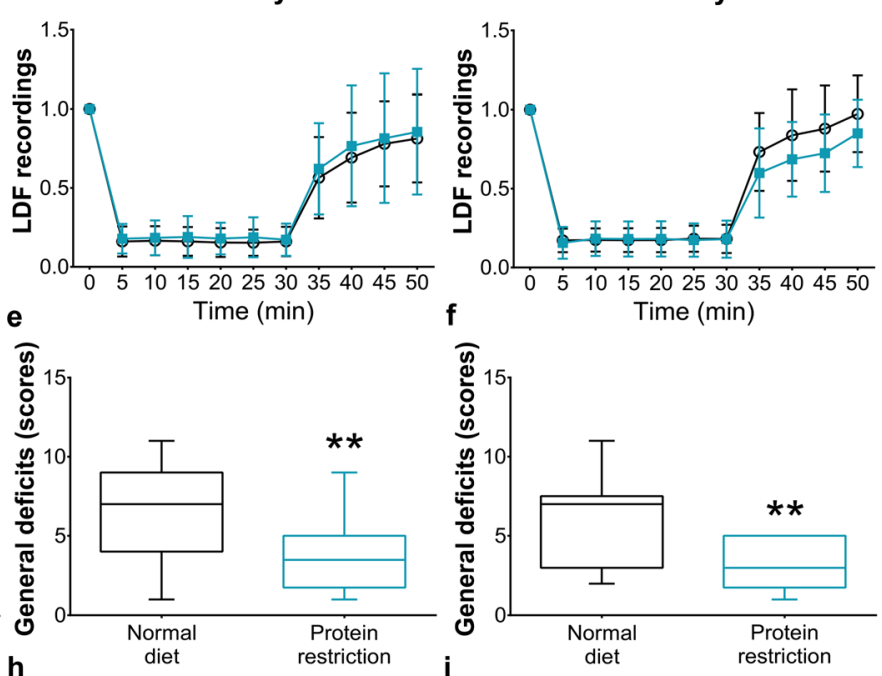

f Time (min)

$\checkmark$ Normal diet

$\bigcirc$ Protein restriction
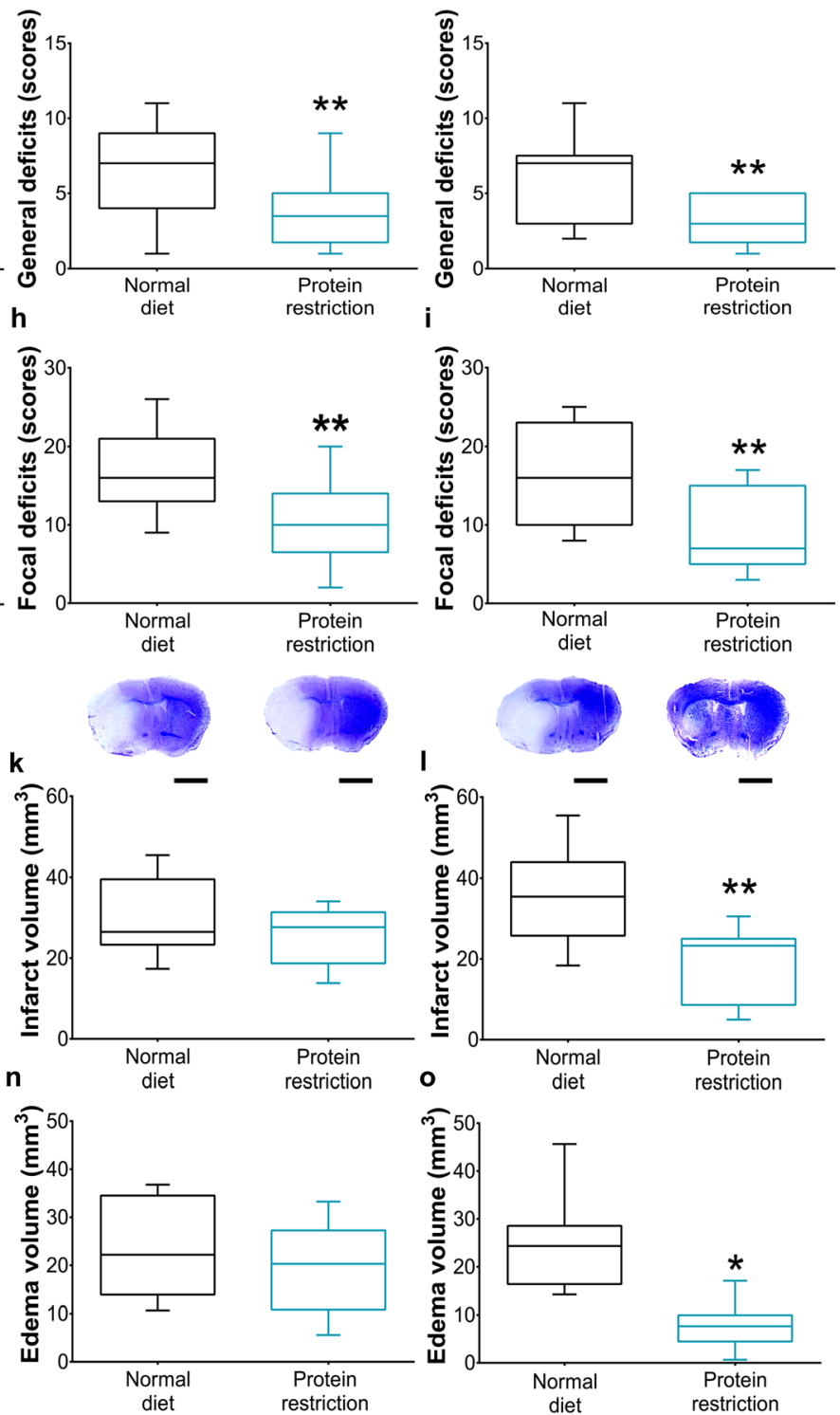
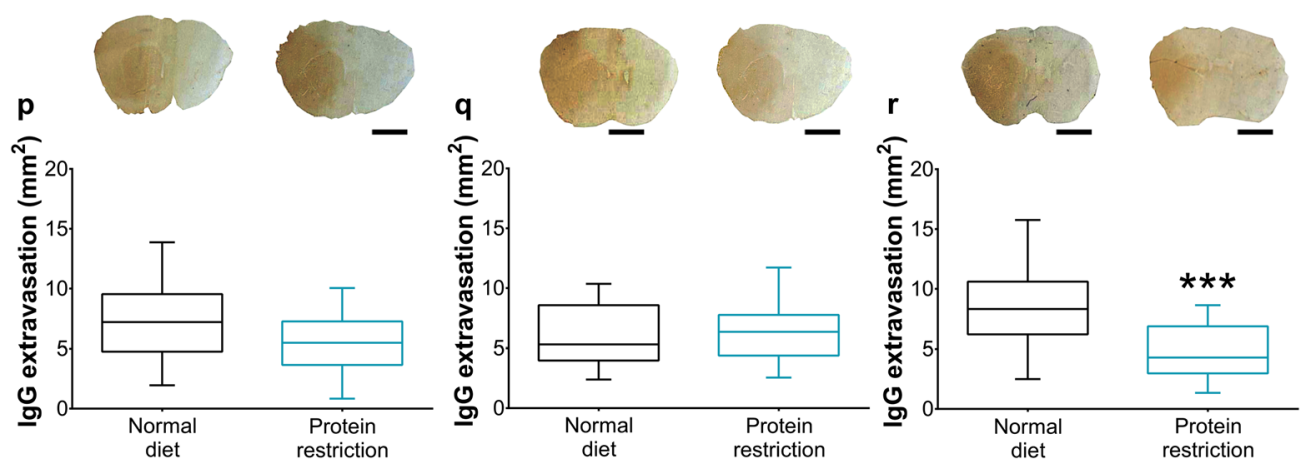
Fig. 1 Protein restriction decreases neurological deficits, infarct volume, brain edema, and blood-brain barrier permeability. a-c Laser Doppler flow (LDF) recordings above the core of the middle cerebral artery territory, $\mathbf{d}-\mathbf{f}$ general neurological deficits evaluated by the Clark score, $\mathbf{g}-\mathbf{i}$ focal neurological deficits examined by the Clark score, $\mathbf{j}-\mathbf{I}$ infarct volume and $\mathbf{m}-\mathbf{0}$ edema volume outlined on cresyl violet-stained brain sections, and (p-r) blood-brain barrier permeability in the striatum assessed by IgG extravasation analysis in mice exposed to normal or proteinreduced diet for 7 days $(\mathbf{a}, \mathbf{d}, \mathbf{g}, \mathbf{j}, \mathbf{m}, \mathbf{p}), 14$ days $(\mathbf{b}, \mathbf{e}, \mathbf{h}, \mathbf{k}, \mathbf{n}, \mathbf{q})$, or 30 days $(\mathbf{c}, \mathbf{f}, \mathbf{i}, \mathbf{l}, \mathbf{o}, \mathbf{r})$, followed by 30 -min intraluminal MCAO and $24 \mathrm{~h}$ reperfusion. Representative photographs are shown. Data are presented as mean \pm S.D. values $(\mathbf{a}-\mathbf{c})$ or median \pm interquartile range box-blots with minimum/maximum data as whiskers $(\mathbf{d}-\mathbf{r})$. Bars in $(\mathbf{e}, \mathbf{f}, \mathbf{g}, \mathbf{h}, \mathbf{i}, \mathbf{l}), 1 \mathrm{~mm}$. $* * * p<0.001 ; * * p<0.01 ; * p<0.05$ compared with corresponding normal diet ( $n=12$ animals/group)

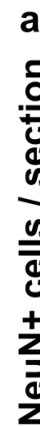
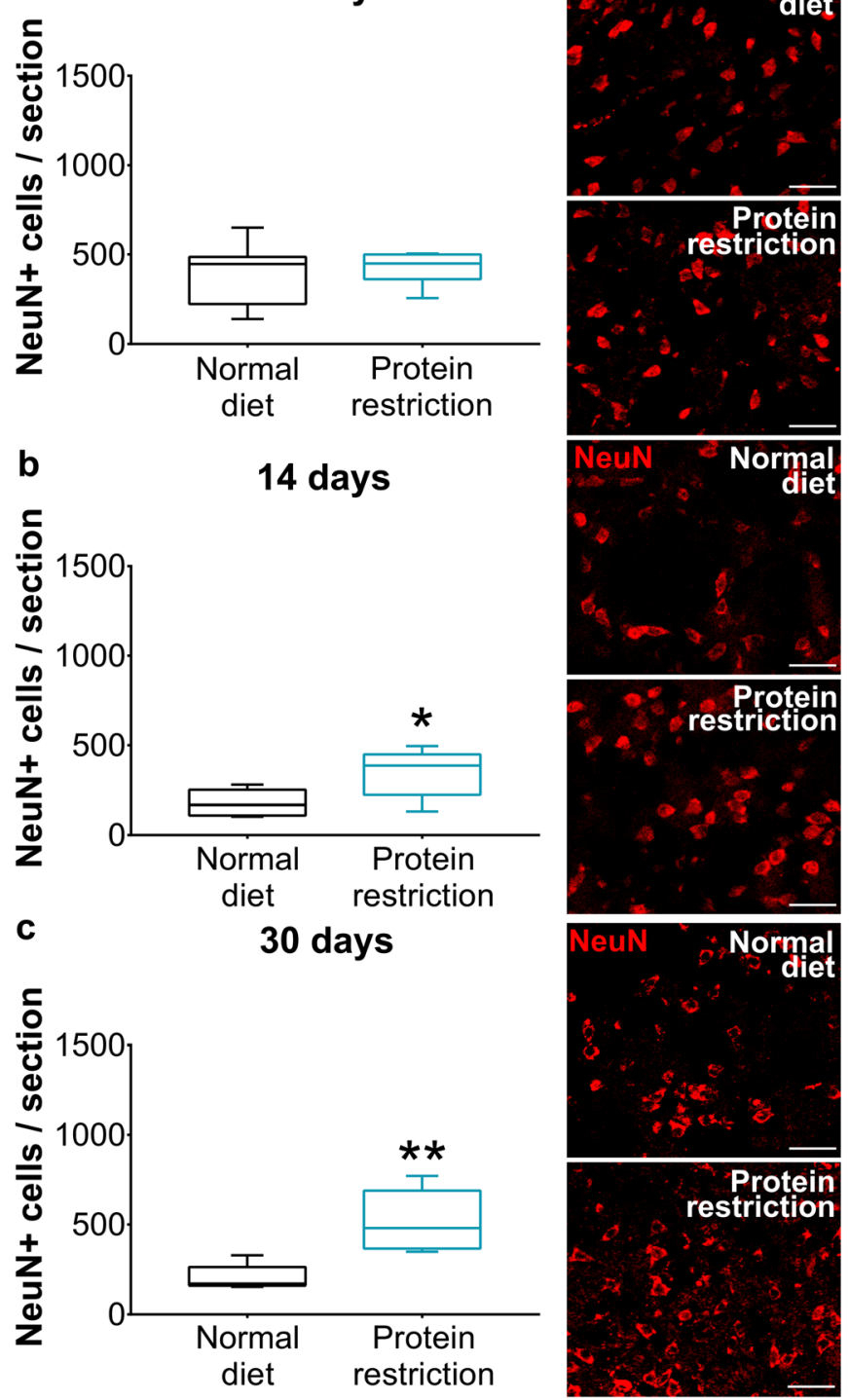

Fig. 2 Protein restriction promotes post-ischemic neuronal survival. a-c Number of NeuN+ surviving neurons and $\mathbf{d}-\mathbf{f}$ number of DNAfragmented, that is, irreversibly injured, TUNEL+ cells in the ischemic striatum of mice exposed to normal or protein-reduced diet over 7 days (a,
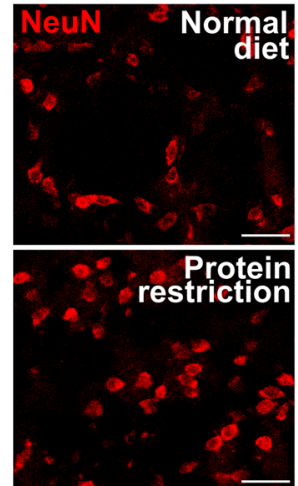

chemiluminescence kit and scanned using amyECL Imager (Thermo Fisher Scientific, Waltham, MA, U.S.A.). Sirt-1 and Gpx-3 abundance was densitometrically evaluated in three independent experiments. The relative abundance of Sirt-1 and Gpx-3 was normalized to protein loading as determined in $\beta$-actin blots.

\section{Statistics}

Statistical analyses were performed using SPSS for Windows. Murinometric data, nutritional data, and LDF recordings were analyzed by repeated-measurement ANOVA followed by
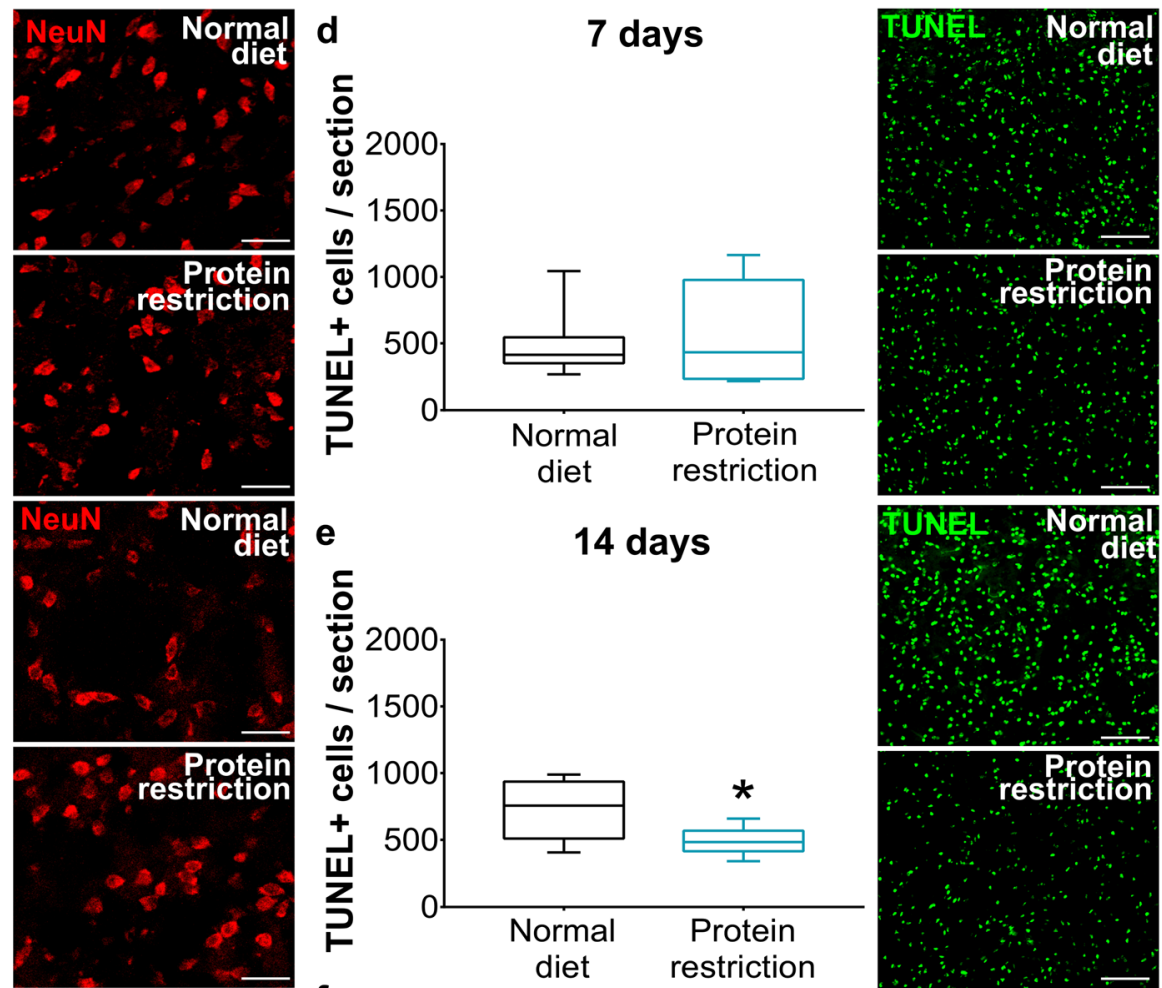

$f$
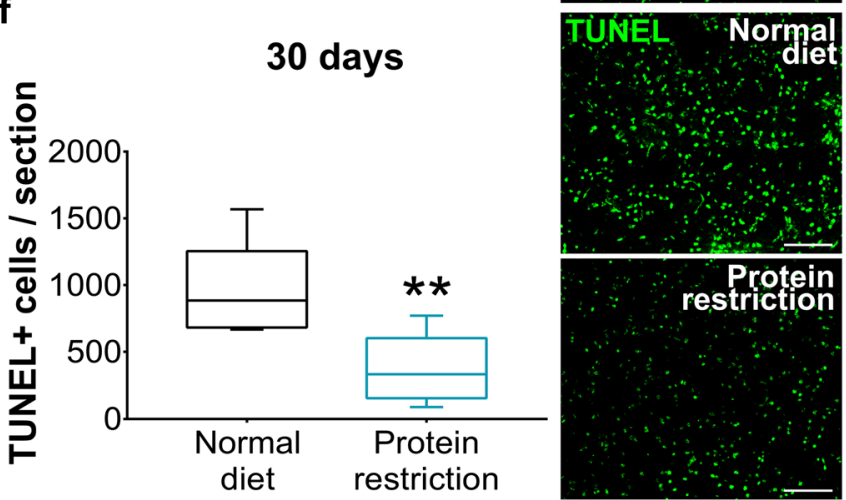

d), 14 days $(\mathbf{b}, \mathbf{e})$, or 30 days (c, f), followed by 30-min intraluminal $\mathrm{MCAO}$ and $24 \mathrm{~h}$ reperfusion. Representative microphotographs are shown. Data are median \pm interquartile range box-blots with minimum/ 
a

b
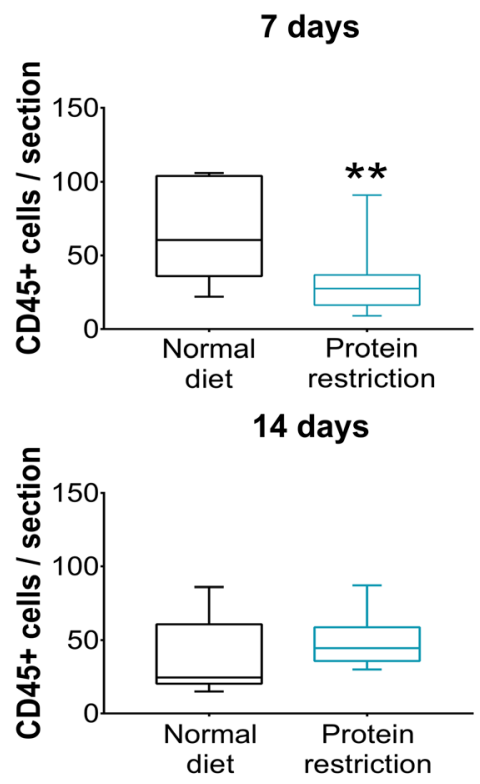

30 days

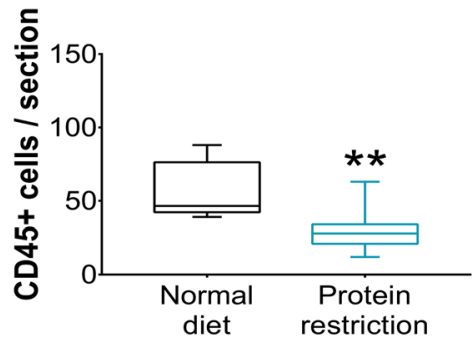

d

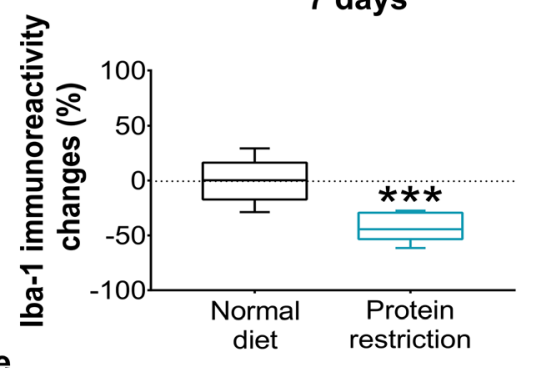

e
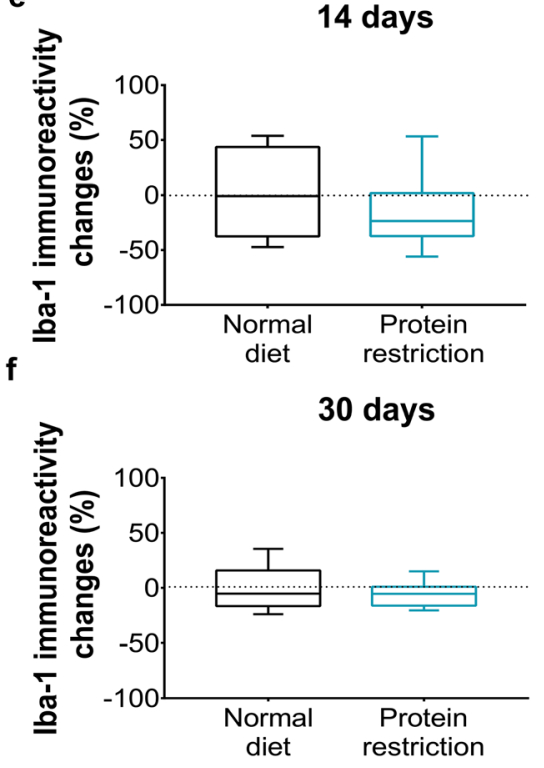
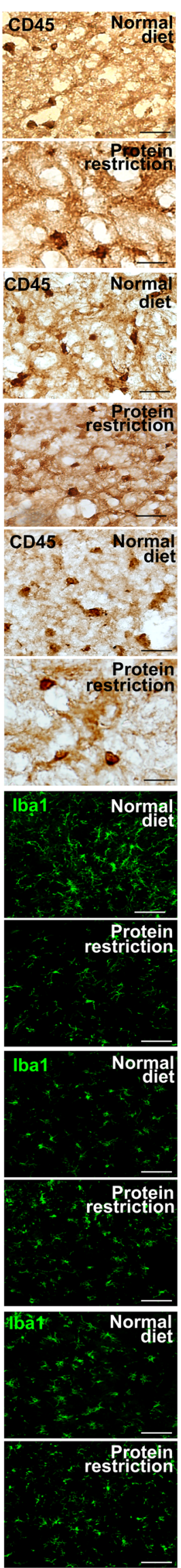

g

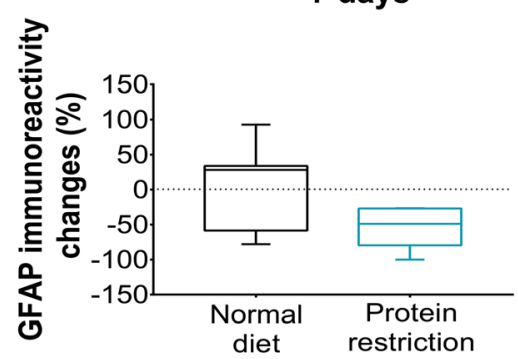

h

14 days

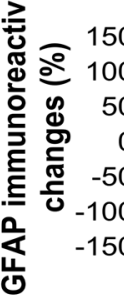

i
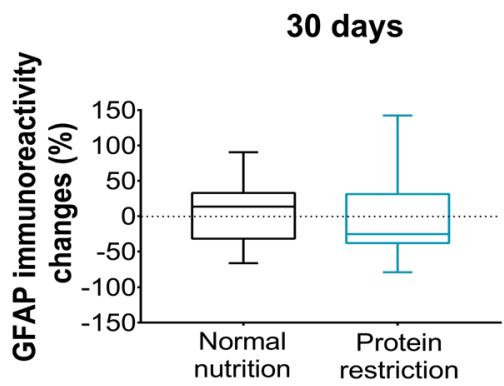

j
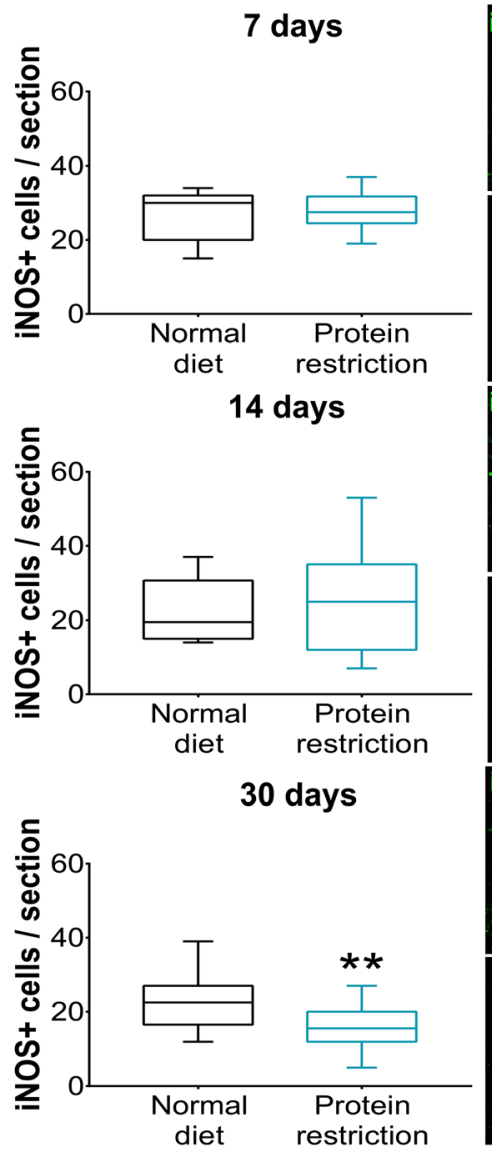
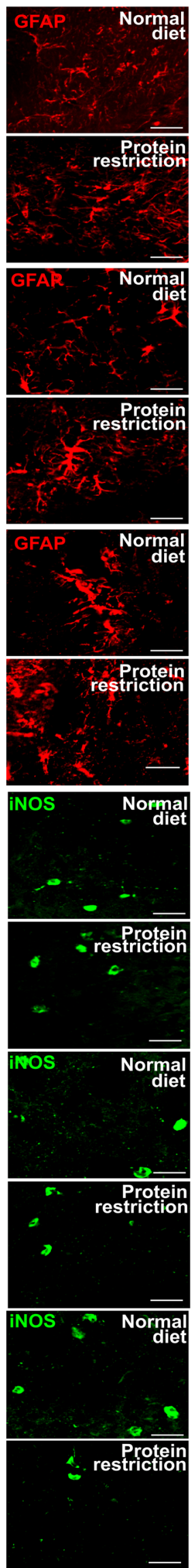
Fig. 3 Protein restriction differentially influences brain leukocyte infiltration, microglial activation, and iNOS formation. a-c Number of CD45+ leukocytes, $\mathbf{d}-\mathbf{f}$ immunoreactivity for microglia marker Iba-1, $\mathbf{g}-\mathbf{i}$ immunoreactivity for astrocytic marker GFAP, and $\mathbf{j}-\mathbf{l}$ number of iNOS+ cells in the ischemic striatum of mice exposed to normal or proteinreduced diet for 7 days $(\mathbf{a}, \mathbf{d}, \mathbf{g}, \mathbf{j}), 14$ days $(\mathbf{b}, \mathbf{e}, \mathbf{h}, \mathbf{k})$, or 30 days $(\mathbf{c}, \mathbf{f}$, i, l), followed by $30 \mathrm{~min}$ intraluminal MCAO and $24 \mathrm{~h}$ reperfusion. Representative microphotographs are shown. Data are median \pm interquartile range box-blots with minimum/maximum data as whiskers. Bars, $100 \mu \mathrm{m}$. ${ }^{*} p<0.01 ; * p<0.05$ compared with normal diet $(n=12$ animals/group)

unpaired $t$ tests as post hoc tests. Neurological deficits, histochemical data, Western blots, and real-time qPCR data were analyzed by $t$ tests. To explore the relationship of protein and calorie intake with infarct volume and neurological deficits, two-tailed Pearson's correlations were computed. LDF recordings, murinometric, nutritional, and real-time qPCR data are presented as mean \pm S.D. values. Neurological deficits, histochemical data, and Western blots are shown as median \pm interquartile range box-blots with minimum/maximum data as whiskers. $P$ values $<0.05$ were defined to indicate statistical significance.

\section{Results}

\section{Moderate Protein Restriction Does Not Alter Major Murinometric and Nutritional Variables but Reduces Plasma LDL and Triglycerides}

Murinometric assessments did not display any changes in body weight (Suppl. Fig. 1A-C) or BMI (Suppl. Fig. 1D-F) over up to 30 days in mice exposed to protein restriction compared with mice receiving normal diet. Likewise, the total amount of food ingested (Suppl. Fig. 1G-I) and calorie intake (Suppl. Fig. 1J-L) prior to MCAO did not differ between groups. After MCAO, until animal sacrifice, animals receiving the protein-reduced diet exhibited higher food (Suppl. Fig. 1G-I) and calorie (Suppl. Fig. 1J-L) intake than animals receiving the normal diet. This stabilized food and calorie intake resembles observations previously made in ischemic mice exposed to intermittent fasting prior to $\mathrm{MCAO}$ [14]. Food and calorie intake post-MCAO in animals on protein restriction was very similar to pre-stroke food and calorie intake. This was not the case in animals on normal diet. In mice exposed to 30 , but not 7 or 14 days protein restriction, plasma cholesterol $[158.3 \pm 19.5$ vs. $252.1 \pm 120.0 \mathrm{mg} / \mathrm{dl}$, $p<0.05]$, LDL [13.6 \pm 14.1 vs. $32.7 \pm 29.7 \mathrm{mg} / \mathrm{dl}, p<0.05]$, and triglyceride $[177.1 \pm 74.6$ vs. $259.3 \pm 147.2 \mathrm{mg} / \mathrm{dl}$, $p<0.05$ ] levels were significantly lower than in mice on normal diet (Suppl. Table 2). Glucose levels did not differ between groups (Suppl. Table 2). The appearance, color, and size of stool samples did not differ between groups (not shown). Behavioral abnormalities (e.g., hypoactivity) or fur changes were absent in mice exposed to protein restriction.

\section{Protein Restriction Decreases Neurological Deficits, Ischemic Injury, Brain Edema, and Blood-Brain Barrier Permeability}

Cerebral LDF recordings during and after MCAO did not differ between groups. LDF reproducibly decreased to $\sim 15-$ $20 \%$ of baseline values during MCAO, followed by the return of LDF to baseline values within $20 \mathrm{~min}$ after reperfusion (Fig. 1a-c). Irrespective of the duration of food modification (7, 14, or 30 days), general (Fig. 1d-f) and focal (Fig. 1g-i) neurological deficits after $24 \mathrm{~h}$ were significantly reduced by protein restriction. Conversely, infarct volume (Fig. $1 \mathrm{j}-1$ ), brain edema (Fig. $1 \mathrm{~m}-\mathrm{o}$ ), and blood-brain barrier permeability assessed by serum IgG extravasation (Fig. 1p-r) was significantly decreased by protein restriction when administered over 30 , but not 7 or 14 days. The number of surviving $\mathrm{NeuN}+$ neurons in the ischemic striatum was significantly

Table 1 Responses of metabolism-related, inflammatory, and anti-oxidant genes in the ischemic brain of mice exposed to protein restriction

\begin{tabular}{|c|c|c|c|c|c|c|c|c|}
\hline Brain & Sirt-1 & $\operatorname{Ig} f-1$ & Insr & Glut-1 & $I l-1 \beta$ & $N f-\kappa b$ & Sod-1 & $G p x-3$ \\
\hline \multicolumn{9}{|l|}{7 days } \\
\hline Normal diet & $1.13 \pm 0.60$ & $3.60 \pm 3.26$ & $1.52 \pm 0.74$ & $1.18 \pm 0.44$ & $5.40 \pm 3.61$ & $1.55 \pm 0.60$ & $0.90 \pm 0.34$ & $0.13 \pm 0.11$ \\
\hline Protein restriction & $1.11 \pm 0.40$ & $2.30 \pm 1.65$ & $1.14 \pm 0.44$ & $1.05 \pm 0.42$ & $4.12 \pm 3.70$ & $1.05 \pm 0.40$ & $0.80 \pm 0.31$ & $0.09 \pm 0.01$ \\
\hline \multicolumn{9}{|l|}{14 days } \\
\hline Normal diet & $0.60 \pm 0.23$ & $1.64 \pm 1.33$ & $1.32 \pm 1.11$ & $1.17 \pm 0.44$ & $3.50 \pm 1.60$ & $3.00 \pm 1.23$ & $1.01 \pm 0.34$ & $0.30 \pm 0.15$ \\
\hline Protein restriction & $0.50 \pm 0.20$ & $1.83 \pm 1.22$ & $0.80 \pm 0.30$ & $0.90 \pm 0.55$ & $3.16 \pm 1.95$ & $2.25 \pm 0.73$ & $1.12 \pm 0.46$ & $0.30 \pm 0.42$ \\
\hline \multicolumn{9}{|l|}{30 days } \\
\hline Normal diet & $0.30 \pm 0.11$ & $1.84 \pm 1.12$ & $0.70 \pm 0.30$ & $1.14 \pm 0.63$ & $5.72 \pm 3.20$ & $2.35 \pm 1.65$ & $0.70 \pm 0.30$ & $0.40 \pm 0.47$ \\
\hline Protein restriction & $0.60 \pm 0.20^{*}$ & $0.83 \pm 0.83$ & $0.63 \pm 0.20$ & $0.90 \pm 0.24$ & $1.64 \pm 0.92 *$ & $1.74 \pm 0.66$ & $0.63 \pm 0.14$ & $5.17 \pm 4.00 *$ \\
\hline
\end{tabular}

Data are real-time quantitative polymerase chain reaction (qPCR) results, expressed as mean $\pm \mathrm{SD}$ values

$* p<0.05$ compared with normal diet ( $n=6$ animals/group; analyzed in triplicates, for which mean values were formed) 
increased (Fig. 2a-c), whereas the number of irreversibly injured, that is, TUNEL+ cells was significantly reduced (Fig. $2 \mathrm{~d}-\mathrm{f}$ ) by 14 days and more pronounced 30 days protein restriction.

To further evaluate links between daily protein intake with infarct volume and neurological deficits, Pearson's correlations were calculated. These Pearson's correlations revealed that after 30 days $[\mathrm{r}=0.387, p=0.001]$, but not 7 days $[\mathrm{r}=$ $0.004, p=0.350]$ or 14 days $[\mathrm{r}=0.071, p=0.206]$ of protein restriction, protein intake was positively correlated with infarct volume (Suppl. Fig. 2). Independent of the duration of protein restriction ( 7,14 , or 30 days), protein intake was positively correlated with general and focal neurological deficits (Suppl. Fig. 2).

\section{Protein Restriction Differentially Influences Brain Leukocyte Infiltration and Microglial Activation}

Protein restriction significantly decreased the invasion of CD45+ leukocytes into ischemic brain tissue, when imposed to 7 or 30 days, but not 14 days (Fig. 3a-c). On the other hand, microglial activation, evaluated by Iba-1 immunohistochemistry, was significantly reduced by 7 days, but not 14 or 30 days protein restriction (Fig. $3 \mathrm{~d}-\mathrm{f})$. Astrogliosis, examined by GFAP immunohistochemistry, was not influenced by protein restriction (Fig. 3g-i). The number of cells immunopositive for iNOS, a marker of pro-inflammatory M1 macrophages/ microglial cells [15], was significantly reduced by protein restriction, when imposed for 30 days, but not 7 or 14 days (Fig. 3j-1). Based on their size and shape, the iNOS+ cells had the appearance of microglial cells.

\section{Protein Restriction Upregulates the NAD-Dependent Deacetylase Sirtuin-1, Downregulates Interleukin-1 $\beta$, and Upregulates Glutathione Peroxidase-3}

Real-time qPCR showed that protein restriction did not alter the expression of metabolism-related, pro-inflammatory, and anti-oxidant genes in ischemic brain tissue, when imposed for 7 or 14 days, but increased the level of sirtuin-1 (Sirt-1) mRNA, which encodes a NAD-dependent deacetylase that stabilizes mitochondrial function and metabolism partly by deacetylating the transcription regulator peroxisome proliferator-activated receptor- $\gamma$ coactivator- $1 \alpha$ (PGC- $1 \alpha)$ [15]; reduced the level of interleukin-1 $\beta$ (Il-1 $\beta$ ) mRNA, which encodes a pro-inflammatory cytokine strongly expressed by M1 microglial cells [15]; and increased the level of glutathione peroxidase-3 (Gpx-3) mRNA, which encodes an antioxidant enzyme that degrades hydrogen peroxide [16, 17], in ischemic brain tissue, when imposed for 30 days (Table 1). Western blots revealed that the abundance of Sirt1 and Gpx-3 proteins was increased after protein restriction over 30 days and in case of Gpx-3 less pronounced also over 14 days (Fig. 4). The metabolic markers insulin-like growth factor-1 (Igf-1) mRNA, which encodes a growth factor with insulin-like properties; insulin receptor (Insr) mRNA; and glucose transporter-1 (Glut-1) mRNA [18] were not influenced by protein restriction, as was nuclear factor- $\kappa b$ $(N f-\kappa b)$ mRNA, which encodes a transcription factor deacetylated by Sirt-1 that controls Il-1 $\beta$ expression [19], or superoxide dismutase-1 (Sod-1) mRNA, which encodes a dismutase degrading superoxide anions to hydrogen peroxide [16] (Table 1).

\section{Protein Restriction Regulates Metabolism-Related, Pro-Oxidant and Anti-Oxidant Genes in the Liver}

Real-time qPCR showed that protein restriction regulated genes encoding metabolism-related genes, pro-oxidant and anti-oxidant enzymes in the liver within 7 days. Thus, Sirt-1 mRNA was upregulated, NADPH oxidase-4 (Nox4) mRNA, which encodes a protein that catalyzes the production of superoxide free radicals by transferring electrons to oxygen from NADP [20], was downregulated, and superoxide dismutase-2 (Sod-2) mRNA and catalase (Cat) mRNA, which encodes another peroxidase [17], were upregulated by protein restriction (Table 2). After 14-day exposure to protein-reduced diet, liver levels of Sirt-1 mRNA, Nox-4 mRNA, and Cat mRNA were reversed to levels in mice receiving normal diet, and liver levels of Sod-1 mRNA, Sod-2 mRNA, and Gpx-3 mRNA were increased (Table 2). Prolonged 30-day protein restriction reregulated metabolism-related and anti-oxidant markers. Thus, Sod-1 mRNA and Sod-2 mRNA were restored to levels in normal diet mice, and Sirt-1 mRNA, Igf-1 mRNA, and Gpx-3 mRNA were elevated (Table 2).

\section{Discussion}

By exposing adult mice to intraluminal MCAO that had been submitted to a protein-reduced diet for 7, 14, or 30 days, we show that protein restriction protects against focal cerebral ischemia. Irrespective of the duration of food modification (7-30 days), post-ischemic neurological deficits were reduced by protein restriction. In contrast to these behavioral improvements, only prolonged protein restriction over 30 days reduced infarct volume, brain edema, and blood-brain barrier permeability. Neuroprotection by protein restriction went along with increased neuronal survival in the ischemic striatum, reduced brain infiltration of CD45+ leukocytes, and reduced the expression of iNOS and interleukin- $1 \beta$. As potential mechanism, increased expression of the NAD-dependent deacetylase Sirt-1 and increased expression of anti-oxidant Gpx-3 were noted in ischemic brain tissue. Robust responses 
a

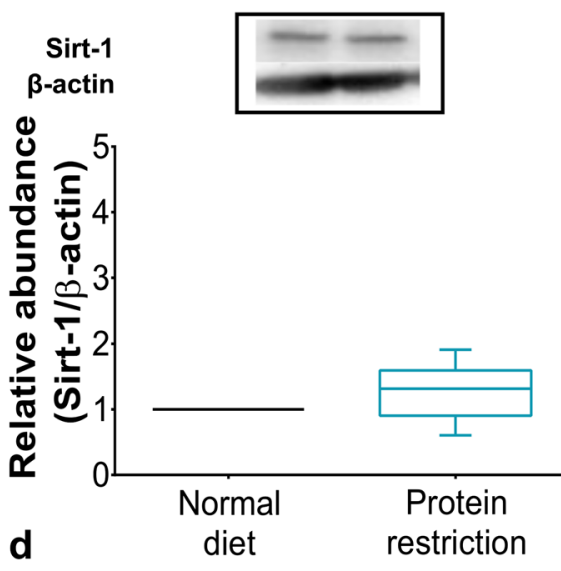

b

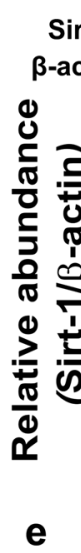

14 days

$\beta$-actin

Gpx-3

$\beta$-actin
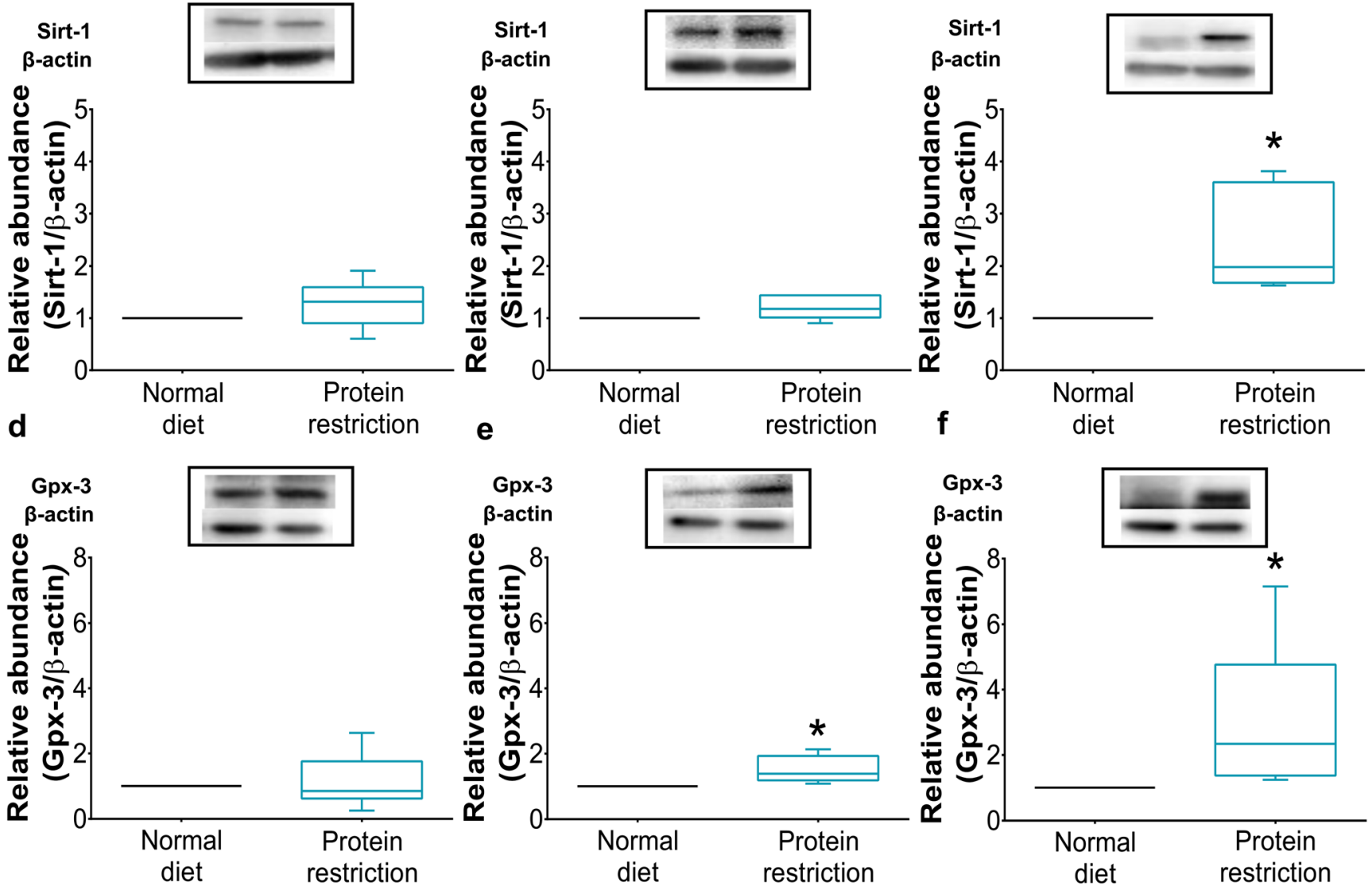

C

30 days

Fig. 4 Protein restriction increases sirtuin-1 and glutathione peroxidase-3 abundance in ischemic brain tissue. Western blot analysis of a-c sirtuin-1 (Sirt-1) and d-f glutathione peroxidase-3 (Gpx-3) protein in ischemic brain tissue of mice exposed to normal or protein-reduced diet for $\mathbf{a}, \mathbf{d}$ 7 days, b, e 14 days, or $\mathbf{c}$, f 30 days, followed by $30 \mathrm{~min}$ intraluminal

of oxidative stress markers, indicating a shift from pro-oxidant (Nox-4) to anti-oxidant (Sod-1, Sod-2, Gpx-3, Cat) enzymes, were detected in the liver.

Previous studies in rat and gerbil models of global and focal cerebral ischemia found that protein restriction compromises neurological recovery in motor-coordination tests $[5,7]$, increases brain inflammation via activation of NF-kb [4], increases neuronal injury [5], and decreases neuronal plasticity, evaluated by the axonal and synaptic proteins growthassociated protein-32, synaptophysin, and synaptosomalassociated protein-25 [6]. These studies have in common that far more severe protein restriction $(0.5-2 \%$ protein, in all studies casein) was imposed for 3 to 4 weeks. Such severe protein restriction results in a reduction in the total amount of food ingested, since the animals refuse this chow [4-7]. Combined protein-energy malnutrition with a loss of body weight was noted in these animals. A single study so far examined consequences of a more moderate diet containing $7 \%$ protein (soybean protein), which, when administered during pregnancy and lactation to mothers, reduced brain injury but augmented sensorimotor deficits and impaired homing behavior of offspring exposed to unilateral cerebral hypoxia-ischemia at 7 days post-birth [8]. The improvement of ischemic injury by protein restriction in this former study goes in line with our study. Unlike this earlier study, we observed an improvement of neurological deficits evaluated with a global and focal behavioral score in adult mice exposed to focal cerebral ischemia. Differences of animal age (adult vs. newborn), ischemia models (intraluminal MCAO vs. unilateral hypoxia-ischemia), diets (casein or soybean protein as protein source), or species (mice vs. rats) may explain the different findings of this previous study [8] and the present one. In this previous study, animals also developed body weight loss [8]. Interestingly, our findings resemble observations following short-term dietary restriction by exposure to a protein-free diet or complete fasting for 6 days in rat models of intraluminal or peripheral MCAO, where similar to the present study reduced infarct volume and decreased motor-coordination deficits were found [21]. Unlike in the present study, body weight was again significantly reduced by both diet protocols [21]. 


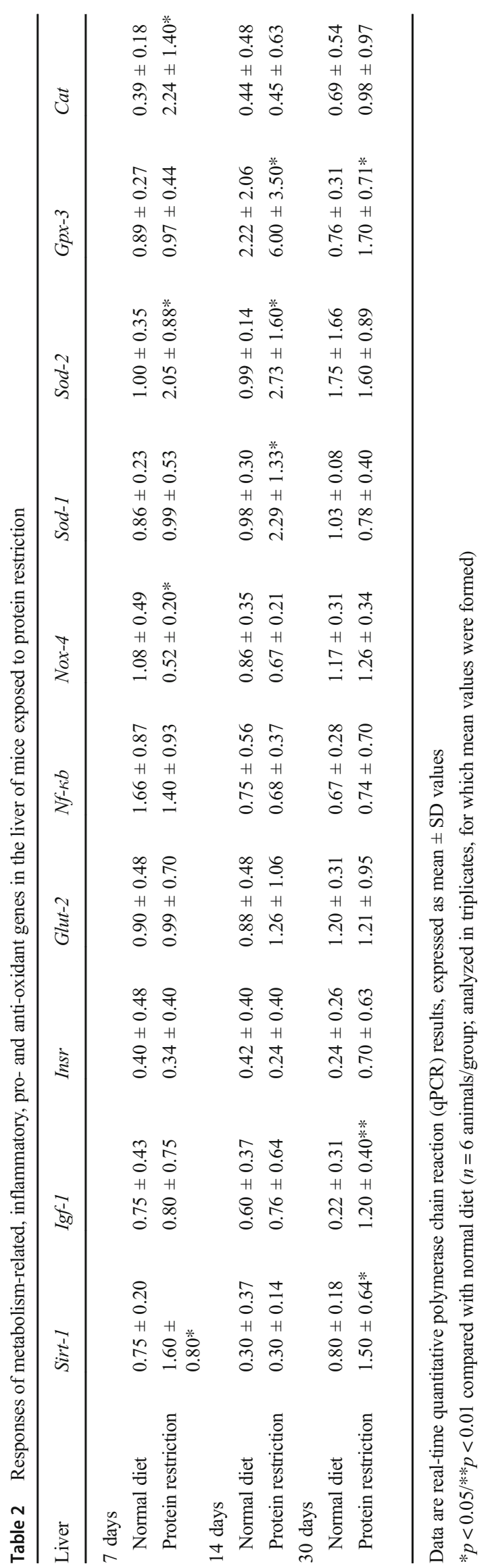


That in our study protein restriction induced neuroprotection without provoking body weight loss is noteworthy. It indicates that, unlike hypothesized earlier [22], body weight loss is not a necessity for neuroprotection to occur subsequent to dietary restriction.

As potential mechanism, protein restriction in the present study reduced plasma cholesterol, LDL, and triglyceride levels and decreased the infiltration of CD45+ leukocytes into the ischemic brain. At the time-point examined ( $24 \mathrm{~h}$ postMCAO), leukocyte infiltrates are predominated by polymorphonuclear neutrophil (PMN) granulocytes. Using strategies of antibody-mediated PMN depletion or prevention of PMN brain entry, we have previously shown that PMN contribute to ischemic injury after intraluminal MCAO [23] and that PMN furthermore mediate injury-aggravating effects of hypercholesterolemia induced by a lipid-rich Western diet [24]. In the present study, the reduced brain leukocyte infiltration after protein restriction was associated with decreased iNOS and Il-1 $\beta$ mRNA levels, which are strongly expressed by proinflammatory M1 microglial cells in the ischemic brain [15]. In our study, the iNOS and $I l-1 \beta$ mRNA responses dissociated from patterns of microglial activation, which was reduced by 7 days, but not 14 or 30 days protein restriction. It is conceivable that microglial differentiation shifted towards a neuroprotective M2 phenotype upon protein restriction. The expression of iNOS and Il-1 $\beta$ under inflammatory conditions is tightly controlled by the transcription factor $N f-\kappa b$ [19], which, as we further showed, was not regulated by protein restriction on the mRNA level.

Neuroprotection by protein restriction was associated with increased expression of the NAD-dependent deacetylase Sirt1 (both on the mRNA and protein level) and increased expression of anti-oxidant $G p x-3$ mRNA in ischemic brain tissue. Independent of the duration of food modification, robust responses of oxidative stress markers (downregulation of prooxidant Nox-4, upregulation of Sod-1/2, Gpx-3, and/or Cat mRNAs) were also found in the liver. Sirt-1 has a large variety of actions in the healthy and injured brain, stabilizing cellular energy metabolism partly by deacetylating PGC- $1 \alpha$ [19], which, besides others, results in the acquisition of ischemic tolerance. Via different downstream targets, mitochondrial energy coupling is promoted, reactive oxygen species formation reduced, and anti-oxidant capacity increased. Our data suggest that Sirt-1 played a role in the regulation of the above pro- and anti-oxidant enzymes. Further studies will be required to elucidate whether elevated Sirt-1 causally contributed to neuroprotection by protein restriction. Interestingly, Sirt- $-^{-/}$was previously found to exacerbate ischemic injury in mice exposed to intraluminal MCAO but failed to abolish protective effects of calorie restriction [25]. The here presented study complements studies on calorie restriction [26], showing that changes in food composition may similarly induce neuroprotection as changes in the total food or calorie amount. In both types of diet modification, anti-inflammatory and anti-oxidant responses seem to be instrumental for the promotion of stroke outcome.

In view of the important role of food composition for stroke management, several questions still remain to be explored, namely (a) effects of diet modifications initiated after focal cerebral ischemia on neurological recovery and brain remodeling, (b) effects of different protein origins (mammalian, poultry vs vegetarian sources) on ischemic injury and neurological recovery, and (c) effects of diet composition depending on nutrition status and the presence of life style-related risk factors (e.g., hyperlipidemia, diabetes). We need to be aware that nutrition and digestion cannot be transferred one-to-one from rodents to human patients. If thoughtfully addressed, rodent studies might allow us to deduct working hypotheses how modifications in food composition could be used for alleviating stroke consequences.

Acknowledgments We thank Britta Kaltwasser and Daniel ManriqueCastaño, the Imaging Center Essen (IMCES), and the Central Laboratory of the University Hospital Essen for technical support.

Author Contributions TSC and DMH designed the study. TSC performed the animal experiments, assisted by EHSM and MS. TSC, LMNM, ARSM, ED, and MS conducted histochemical and molecular biological studies. DMH and CK provided infrastructural support. TSC, EHSM, LMNM, ARSM, ED, and DMH analyzed the data. TSC and DMH drafted the manuscript. All the authors finalized it.

Funding Supported by the Brazilian National Council for Scientific and Technological Development (CNPq)/German Academic Exchange Service (DAAD) (290076/2014-5, to TSC) and German Research Foundation (DFG; HE3173/11-1, to DMH).

\section{Compliance with Ethical Standards}

Conflict of Interest The authors declare that they have no conflict of interest.

Ethical Approval All applicable international, national, and/or institutional guidelines for the care and use of animals were followed. This article does not contain any studies with human participants performed by any of the authors.

Open Access This article is distributed under the terms of the Creative Commons Attribution 4.0 International License (http:// creativecommons.org/licenses/by/4.0/), which permits unrestricted use, distribution, and reproduction in any medium, provided you give appropriate credit to the original author(s) and the source, provide a link to the Creative Commons license, and indicate if changes were made.

\section{References}

1. Bernstein AM, Pan A, Rexrode KM, Stampfer M, Hu FB, Mozaffarian D, Willett WC (2012) Dietary protein sources and the risk of stroke in men and women. Stroke 43:637-644. https:// doi.org/10.1161/STROKEAHA.111.633404 
2. Kaluza J, Wolk A, Larsson SC (2012) Red meat consumption and risk of stroke: a meta-analysis of prospective studies. Stroke 43: 2556-2560. https://doi.org/10.1161/STROKEAHA.112.663286

3. Kimura Y, Yamada M, Kakehi T, Itagaki A, Tanaka N, Muroh Y (2017) Combination of low body mass index and low serum albumin level leads to poor functional recovery in stroke patients. $\mathrm{J}$ Stroke Cerebrovasc Dis 26:448-453. https://doi.org/10.1016/j. jstrokecerebrovasdis.2016.10.008

4. Ji L, Nazarali AJ, Paterson PG (2008) Protein-energy malnutrition increases activation of the transcription factor, nuclear factor $\mathrm{kB}$, in the gerbil hippocampus following global ischemia. J Nutr Biochem 19:770-777. https://doi.org/10.1016/j.jnutbio.2007.09.011

5. Bobyn PJ, Corbett D, Saucier DM, Noyan-Ashraf MH, Juurlink BHJ, Paterson PG (2005) Protein-energy malnutrition impairs functional outcome in global ischemia. Exp Neurol 196:308-315. https://doi.org/10.1016/j.expneurol.2005.08.006

6. Smith SE, Figley SA, Schreyer DJ, Paterson PG (2014) Proteinenergy malnutrition developing after global brain ischemia induces an atypical acute-phase response and hinders expression of GAP43. PLoS One 9:e107570. https://doi.org/10.1371/journal.pone. 0107570

7. Alaverdashvili M, Caine S, Li X, Hackett MJ, Bradley MP, Nichol H, Paterson PG (2018) Protein-energy malnutrition exacerbates stroke-induced forelimb abnormalities and dampens neuroinflammation. Transl Stroke Res 9:622-630. https://doi.org/10.1007/ s12975-018-0613-3

8. Sanches EF, Arteni NS, Spindler C, Moysés F, Siqueira IR, Perry ML, Netto CA (2012) Effects of pre- and postnatal protein malnutrition in hypoxic-ischemic rats. Brain Res 1438:85-92. https://doi. org/10.1016/j.brainres.2011.12.024

9. Novelli ELB, Diniz YS, Galhardi CM, Ebaid GMX, Rodrigues HG, Mani F, Fernandes AAH, Cicogna AC et al (2007) Anthropometrical parameters and markers of obesity in rats. Lab Anim 41:111-119. https://doi.org/10.1258/002367707779399518

10. Reitmeir R, Kilic E, Kilic Ü, Bacigaluppi M, ElAli A, Salani G, Pluchino S, Gassmann M et al (2011) Post-acute delivery of erythropoietin induces stroke recovery by promoting perilesional tissue remodelling and contralesional pyramidal tract plasticity. Brain. 134:84-99. https://doi.org/10.1093/brain/awq344

11. Zechariah A, Elali A, Hermann DM (2010) Combination of tissueplasminogen activator with erythropoietin induces blood-brain barrier permeability, extracellular matrix disaggregation, and DNA fragmentation after focal cerebral ischemia in mice. Stroke 41: 1008-1012. https://doi.org/10.1161/STROKEAHA.109.574418

12. Clark WM, Lessov NS, Dixon MP, Eckenstein F (1997) Monofilament intraluminal middle cerebral artery occlusion in the mouse. Neurol Res 19:641-648. https://doi.org/10.1080/ 01616412.1997.11740874

13. Livak KJ, Schmittgen TD (2001) Analysis of relative gene expression data using real-time quantitative PCR and the 2- $\Delta \Delta \mathrm{CT}$ method. Methods 25:402-408. https://doi.org/10.1006/meth.2001.1262

14. Ciobanu O, Elena Sandu R, Tudor Balseanu A, Zavaleanu A, Gresita A, Petcu EB, Uzoni A, Popa-Wagner A (2017) Caloric restriction stabilizes body weight and accelerates behavioral recovery in aged rats after focal ischemia. Aging Cell 16:1394-1403. https://doi.org/10.1111/acel.12678
15. Lee JH, Wei ZZ, Cao W, Won S, Gu X, Winter M, Dix TA, Wei L et al (2016) Regulation of therapeutic hypothermia on inflammatory cytokines, microglia polarization, migration and functional recovery after ischemic stroke in mice. Neurobiol Dis 96:248-260. https://doi.org/10.1016/j.nbd.2016.09.013

16. Lubos E, Loscalzo J, Handy DE (2010) Glutathione peroxidase-1 in health and disease: from molecular mechanisms to therapeutic opportunities. Antioxid Redox Signal 15:1957-1997. https://doi.org/ 10.1089/ars.2010.3586

17. Ighodaro OM, Akinloye OA (2017) First line defence antioxidantssuperoxide dismutase (SOD), catalase (CAT) and glutathione peroxidase (GPX): their fundamental role in the entire antioxidant defence grid. Alexandria J Med 54:287-293. https://doi.org/10. 1016/j.ajme.2017.09.001

18. Fernandez AM, Hernandez E, Guerrero-Gomez D, MirandaVizuete A, Torres Aleman I (2018) A network of insulin peptides regulate glucose uptake by astrocytes: potential new druggable targets for brain hypometabolism. Neuropharmacology. 136:216222. https://doi.org/10.1016/j.neuropharm.2017.08.034

19. Perez-Pinzon M, Koronowski K (2015) Sirt1 in cerebral ischemia. Brain Circ 1:69-78. https://doi.org/10.4103/2394-8108.162532

20. Kleikers P, Wingler K, Hermans JJR et al (2012) Neuroprotection after stroke by targeting NOX4 as a source of oxidative stress. Antioxid Redox Signal 18:1418-1427. https://doi.org/10.1089/ars. 2012.4797

21. Varendi K, Airavaara M, Anttila J, Vose S, Planken A, Saarma M, Mitchell JR, Andressoo JO (2014) Short-term preoperative dietary restriction is neuroprotective in a rat focal stroke model. PLoS One 9:e93911. https://doi.org/10.1371/journal.pone.0093911

22. Yi-Fang T, Pei-Jung L, Chao-Ching $\mathrm{H}$ et al (2012) Moderate dietary restriction reduces p53-mediated neurovascular damage and microglia activation after hypoxic ischemia in neonatal brain. Stroke 43:491-498. https://doi.org/10.1161/STROKEAHA.111.629931

23. Neumann J, Riek-Burchardt M, Herz J, Doeppner TR, König R, Hütten H, Etemire E, Männ L et al (2015) Very-late-antigen-4 (VLA-4)-mediated brain invasion by neutrophils leads to interactions with microglia, increased ischemic injury and impaired behavior in experimental stroke. Acta Neuropathol 129:259-277. https:/ doi.org/10.1007/s00401-014-1355-2

24. Herz J, Hagen SI, Bergmüller E, Sabellek P, Göthert JR, Buer J, Hansen W, Hermann DM et al (2014) Exacerbation of ischemic brain injury in hypercholesterolemic mice is associated with pronounced changes in peripheral and cerebral immune responses. Neurobiol Dis 62:456-468. https://doi.org/10.1016/j.nbd.2013.10. 022

25. Liu AJ, Guo JM, Liu W, Su FY, Zhai QW, Mehta JL, Wang WZ, Su DF (2013) Involvement of arterial baroreflex in the protective effect of dietary restriction against stroke. J Cereb Blood Flow Metab 33: 906-913. https://doi.org/10.1038/jcbfm.2013.28

26. Carvalho TSC, Sanchez-Mendoza EH, Melo LMN et al (2019) Neuroprotection induced by energy and protein-energy undernutrition is phase-dependent after focal cerebral ischemia in mice. Transl Stroke Res. https://doi.org/10.1007/s12975-019-00700-3

Publisher's Note Springer Nature remains neutral with regard to jurisdictional claims in published maps and institutional affiliations. 